Health Services and Population Research Department at the Institute of Psychiatry (King's College, London) in London.

\section{Simon Groen,}

De Evenaar Center for Transcultural Psychiatry North Netherlands, in Beilen, The Netherlands.

\section{Rob van Dijk,}

i-psy intercultural psychiatry, Parnassia Psychiatric Institute, in The Hague, The Netherlands.

Adil Qureshi,

Department of Psychiatry, University Hospital Vall d'Hebron, CIBERSAM, Universitat Autònoma de Barcelona, in Barcelona, Spain.

Francisco Collazos,

Department of Psychiatry, University Hospital Vall d'Hebron, CIBERSAM, Universitat Autònoma de Barcelona, in Barcelona, Spain.

\section{Cécile Rousseau,}

Division of Social \& Transcultural Psychiatry, Department of Psychiatry, at McGill University in Montreal, Quebec, Canada.

\section{Luis Caballero,}

Psychiatry Service at Hospital Universitario Puerta de Hierro de Majadahonda and the Department of Psychiatry, Universidad Autónoma, in Madrid, Spain.

Mar Ramos, and Department of Psychiatry, University Hospital Vall d'Hebron, CIBERSAM, Universitat Autònoma de Barcelona, in Barcelona, Spain.

\section{Francis Lu}

Department of Psychiatry and Behavioral Sciences at the University of California, Davis, in Sacramento, California.

\section{Abstract}

The Outline for Cultural Formulation (OCF) introduced with DSM-IV provided a framework for clinicians to organize cultural information relevant to diagnostic assessment and treatment planning. However, use of the OCF has been inconsistent, raising questions about the need for guidance on implementation, training, and application in diverse settings. To address this need, DSM-5 introduced a cultural formulation interview (CFI) that operationalizes the process of data collection for the OCF. The CFI includes patient and informant versions and 12 supplementary modules addressing specific domains of the OCF. This article summarizes the literature reviews and analyses of experience with the OCF conducted by the DSM-5 Cross-Cultural Issues Subgroup (DCCIS) that informed the development of the CFI. We review the history and contents of the DSM-IV OCF, its use in training programs, and previous attempts to render it operational through questionnaires, protocols, and semi-structured interview formats. Results of research based on the OCF are discussed. For each domain of the OCF, we summarize findings from the DCCIS that led to content revision and operationalization in the CFI. The conclusion discusses training and implementation issues essential to service delivery. 
Culture shapes every aspect of patient care in psychiatry, influencing when, where, how, and to whom patients narrate their experiences of illness and distress (Kirmayer, 2006), the patterning of symptoms (Klein-man, 1977), and the models clinicians use to interpret and understand symptoms in terms of psychiatric diagnoses (Kleinman, 1987). Culture also shapes patients' perceptions of care, including what types of treatment are acceptable and for how long (Lewis-Fernández et al., 2013). Even when patients and clinicians share similar cultural, ethnic or linguistic backgrounds, culture impacts care through other influences on identity, such as those due to gender, age, class, race, occupation, sexual orientation, and religion (Lu, Lim, \& Mezzich, 1995). Culture affects the clinical encounter for every patient, not only underserved minority groups, and cultural formulation therefore is an essential component of any comprehensive assessment.

The publication of the Outline for Cultural Formulation (OCF) in DSM-IV (American Psychiatric Association [APA], 1994) was a milestone for cultural psychiatry, acknowledging culture's relevance to mainstream psychiatry. The OCF was a concise list of cultural topics organized by broad domains for clinicians to consider in the assessment of patients. The OCF was developed through literature reviews conducted by the National Institute of Mental Health-sponsored Group on Culture and Diagnosis in 1991-1993 (Mezzich, 2008; Mezzich et al., 1999). The goal of the OCF was to help clinicians identify cultural and contextual factors relevant to diagnosis and treatment (Lewis-Fernández \& Díaz, 2002; Mezzich, Caracci, Fábrega, \& Kirmayer, 2009). The DSM-IV explained that the OCF was "meant to supplement the multiaxial diagnostic assessment and to address difficulties that may be encountered in applying DSM-IV criteria in a multicultural environment" (APA, 1994, p. 897). The OCF was reprinted without revision in DSM-IV-TR (APA, 2000).

Two decades of experience with the OCF led to its revision for DSM-5 (APA, 2013) and the development of semi-structured interviews to make the process of collecting information for the OCF more operational. This set of interviews is known collectively as the Cultural Formulation Interview (CFI) and consists of a core 16-item questionnaire supplemented by 12 modules for further assessment as well as an informant version to obtain material from care-givers (APA, 2013; available at http://www.psych.org/practice/dsm/dsm5/onlineassessment-measures).

This article presents the scientific back-ground and rationale for the OCF revisions and new CFI-related material in DSM-5, included in the Cultural Formulation chapter and the APA website. We summarize the information used to refine the OCF and develop the CFI for $D S M-5$. We combine two sources of evidence: (1) data from a series of literature reviews conducted by members of the DSM-5 Cross-Cultural Issues Subgroup (DCCIS) and (2) a summary of the main conceptual issues raised by the DCCIS during the revision process.

\section{THE DSM-5 CROSS-CULTURAL ISSUES SUBGROUP}

The DCCIS was part of the larger Gender and Cross-Cultural Issues Study Group and composed of international experts in culture and mental health. The authors of this review were members, advisors, or collaborators of the Subgroup, chaired by Roberto Lewis- 
Fernández and Kimberly Yonkers. Our goal was to improve the assessment of culture within psychiatric diagnosis and treatment planning. Specifically, the Subgroup was charged by the DSM-5 Task Force with making recommendations on racial, ethnic, cultural, and contextual issues to the DSM-5 Work Groups related to differences in risk factors, precipitants, symptom presentations, prevalence, symptom severity, and course of illness.

In addition, the DCCIS undertook a critical review of the DSM-IV OCF. DCCIS participants prepared literature reviews on the whole OCF, each of its four domains, and on implementation questions raised by its use in clinical care (e.g., best practices; special populations in need of attention such as children, the elderly, or immigrants and refugees; format and content of interviews, protocols, and questionnaires operationalizing the Outline). They were also asked to recommend revisions to the OCF for DSM-5.

Based on this information, the OCF was revised slightly for $D S M-5$, mostly by making the $D S M-I V$ text more explicit in places. Examples of this clarification include: incorporating elements of cultural identity not mentioned in DSM-IV (e.g., religious affiliation, sexual orientation); instructing clinicians to identify actual stressors and supports in the patient's environment as well as their interpretation of the patient's illness; and mention of the potential impact of racism and discrimination on the clinician-patient relationship.

More substantial changes related to making the OCF more user friendly by developing an interview to guide the process of clinical data collection. An initial 14-item interview was developed largely through previous question lists, interview protocols, and interviews that operationalized the OCF (see Table 1); most authors of these approaches were members of the DCCIS. Questions were formulated, discussed, and debated in 2010 and 2011 in biweekly conference calls, supported by the DSM-5 development process. The resulting 14item version of the CFI was tested in a field trial from November 2011 to November 2012 at 12 clinical sites in the United States, Canada, Peru, the Netherlands, Kenya, and India. This trial utilized a standardized training video (http://www.ucl.ac.uk/ccs/specialist-services/\#cfi) to evaluate the CFI's feasibility, acceptability, and clinical utility among patients and clinicians. Field trial results informed the final 16-item version in DSM-5. Supplementary modules were also developed for more comprehensive assessment. Some modules expand sections of the core CFI and others were developed for use with school-age children and adolescents, elderly individuals, immigrants and refugees, and caregivers (Table 2). An informant version was prepared to elicit collateral information from parents and others in the patient's support system. These instruments help clinicians tailor the comprehensiveness of cultural assessment through a "telescoping" approach. Because of ongoing data analysis, a description of the development of the final CFI from the field trial results will appear in future publications.

\section{METHODS FOR THE LITERATURE REVIEW}

An initial literature search was conducted on Medline and PsycInfo for all publications since 1994 when DSM-IV was published. The phrases "cultural formulation," "cultural assessment," "cultural consultation," and "cultural interview" were paired with the term "mental." The search produced 1,153 articles from Medline and 111 articles on PsycInfo. 
Abstracts were reviewed for relevance by the first two authors and full texts were retrieved for all original publications with data from the OCF. A list of 140 pertinent titles was circulated to the coauthors, who augmented the list individually by inspection of bibliographies from retrieved articles, by additional searches of specific topics that pertain to the Outline (such as "cultural identity"), by bibliographies from general articles on crosscultural assessment and explanatory models, and by references from 1965-1994, when appropriate. Coauthors accessed additional material in English, Danish, Dutch, French, Norwegian, Spanish, and Swedish.

\section{RESULTS}

In what follows, we focus on the deliberations of the DCCIS, including results of the literature reviews. We first review the original DSM-IV OCF, its use in training programs, and previous attempts to operationalize it through questionnaires, protocols, and semistructured interviews. Second, results of research based on the OCF are discussed. Next, for each OCF domain, we summarize findings from the literature reviews and discussions by the DCCIS that led to the CFI. We follow the same process to identify implementation issues in service delivery. Focusing on previous operationalizations of the OCF, we highlight common interviewing approaches to elicit the OCF domains that were included in the CFI.

\section{Content, Use in Training, and Previous Operationalization of the OCF}

The DSM-IV OCF organized clinical information in four domains: (1) cultural identity of the individual, (2) cultural explanations of illness, (3) cultural interpretation of psychosocial stressors, supports, and levels of functioning, and (4) cultural elements of the patientclinician relationship. Information from these domains influencing diagnosis and treatment were summarized and synthesized in a fifth section to provide an overall formulation (APA, 1994). The DSM-IV Culture and Diagnosis Group intended for the Outline to provide an account of patients' illness experience that captured not just symptoms but also personal and cultural meanings and social context (Mezzich, 1995). The cultural formulation would then be presented in a narrative that explained causal links and meanings in a way that extended a bio-psycho-social formulation (Kleinman, 1988; Lewis-Fernández \& Diaz, 2002). Social theory guided delineation of the domains, including the role of identity in clinical presentation (domain 1), cultural meanings and explanatory models of illness (domain 2), social networks providing support or stressors affecting functional capacity (domain 3), and the professional's reflections on the patient-clinician relationship (domain 4) (Mezzich, 2008). Subsequent publications have considered how clinical assessment should cover the four domains of the OCF (e.g., Group for the Advancement of Psychiatry [GAP], 2001; Lewis-Fernández, 1996; Lim, 2006; Lu et al., 1995; Mezzich et al., 2009).

The OCF has been used worldwide. Educators have utilized it in training programs in Canada (Fung, Andermann, Zaretsky, \& Lo, 2008; Kirmayer, Rousseau, Guzder, \& Jarvis, 2008a; Kirmayer et al., 2012), Denmark (Østerskov, 2011), India (Jadhav \& Jain, 2012), the Netherlands (Beijers \& Van Dijk, 2012), Norway (Bäärnhielm, Scarpinati Rosso, \& Pattyi, 2010), Spain (Caballero, 2008), Sweden (Bäärnhielm, Scarpinati Rosso, \& Pattyi, 2007; 
Bäärnhielm \& Gustafsson, 2010), the UK (Jadhav, 2010a, 2010b), and the US (Harris, McQuery, Raab, \& El-more, 2008; Lim, 2006; Lim, Diamond et al., 2008a; Lim, Luo et al., 2008b). In a purposive sample of 20 preceptors from U.S. adult psychiatry residency programs, $70 \%$ had at least one class on the OCF, usually during the first two years (Hansen et al., 2013). Similarly, centers providing outpatient services to migrants and refugees in Sweden (Scar-pinati Rosso \& Bäärnhielm, 2012) and the Netherlands (Rohlof, Knipscheer, \& Kleber, 2009) have used the OCF for standard clinical assessment.

While much of this work has found the OCF a useful clinical tool, problems have also been identified. Guidance has been lacking on when, with whom, and why to use the OCF (Cuéllar \& Paniagua, 2000), and it may duplicate information from the clinical assessment (Caballero, 2009). Clinicians have struggled to find ways to cover the four domains within the time constraints of various practice settings (Lewis-Fernández, 2009). Some subsections of the OCF may be imprecise and overlapping and some important topics were absent (Ton $\& \mathrm{Lim}, 2006)$. It is not clear which components of the OCF are particularly relevant for treatment planning and adaptation of clinical approaches and should be emphasized in practice (Mezzich et al., 2009). Use of the OCF with children (Aggarwal, 2010a; Rousseau, Measham \& Bathiche-Suidan, 2009), immigrants and refugees (Groen, 2009a; Rohlof et al., 2009), homeless populations (Jadhav, 2001a), those with limited literacy (Jadhav \& Jain, 2012), and the elderly (Aggarwal, 2010b; Takeshita \& Ahmed, 2004) may require collateral sources of information or local adaptations. The lack of a standard approach to the OCF has hindered generalizable research (Alar-cón, 2009; Mezzich et al., 2009).

Such concerns prompted efforts to make the OCF more operational, with lists of suggested questions, protocols for topics to be covered during OCF-based assessments, and semistructured interviews (Table 1). These approaches were developed in Canada (Kirmayer et al., 2001), the Netherlands (Groen, 2009b; Rohlof, 2008; Rohlof, Loevy, Sassen, \& Hehnich, 2002; van Dijk, Beijers, \& Groen, 2012), Sweden (Bäärnhielm \& Scarpinati Rosso, 2009), the United States (Mezzich et al., 2009), the United Kingdom (Jadhav, 2010a, 2010b), and Denmark (Østerskov, 2011). All of these interviews were designed to enhance clinical assessment and treatment planning rather than to elicit research data. In related work, interviews were developed for research focusing on cultural epidemiology and illness narratives, including the Explanatory Model Interview Catalogue (Weiss, 2001) and the McGill Illness Narrative Interview (Groleau, Young, \& Kirmayer, 2006). Developers of many of these instruments were members of the DCCIS, and their experience informed the preparation of a new cultural formulation interview for $D S M-5$.

In refining the $\mathrm{OCF}$ and developing the CFI, we were sensitive to the potential pitfalls of some simplistic approaches to cultural competence that may stereotype groups through race, ethnicity, or religion. Our framework adopted a person-centered approach that aimed to be attentive to what is at stake for the patient (Kleinman \& Benson, 2006). Rather than approaching culture as a checklist of traits, factors, or dimensions, the OCF was intended to be based on a "mini-ethnography" that explored the patient's own interpretation of illness experience. Without training, however, many practitioners may struggle with this ethnographic approach (Aggarwal \& Rohrbaugh, 2011). A key challenge for DSM-5, therefore, was to provide guidelines for a patient-centered assessment to address the topics 
of the OCF without reducing the exercise to a formality. Explaining the rationale and providing sample questions for each OCF domain aimed to strike a balance between explicit direction and flexibility for application in diverse settings.

\section{Research Results from Use of the OCF}

Most work on the OCF has consisted of case studies published in the journals Culture, Medicine, and Psychiatry and Trans-cultural Psychiatry. The most extensive literature beyond case studies comes from a cultural consultation service (CCS) at McGill University which makes systematic use of an expanded version of the OCF as an interview guide for cultural consultants assisted by interpreters and culture brokers as needed. Findings from the use of this interview are discussed in a multidisciplinary case conference to develop a cultural formulation. In a study of 100 consecutive patients seen through the CCS, Kirmayer and colleagues (2003) demonstrated common cultural misunderstandings in practice, such as incomplete assessments, missing or incorrect diagnoses, failed rapport, poor adherence, and inappropriate treatment. Sixty consultants and culture brokers on this service were administered a survey inquiring about their use of the DSM-IV OCF and the CCS version; many were unfamiliar with the DSM-IV tool or had not used it before, but fully $93 \%$ found the expanded OCF interview to be useful (Kirmayer, Thombs et al., 2008c). In a retrospective chart review of 323 patients seen through the CCS across 10 years, 34 (49\%) of 70 cases with a referral diagnosis of psychotic disorder were re-diagnosed as nonpsychotic after OCF-based assessment, and $12(5 \%)$ of 253 cases with referral diagnoses of non-psychotic disorders were re-diagnosed with a psychotic disorder $(p<.001)$ (Adeponle et al., 2012). Many of the patients misdiagnosed with a psychotic disorder were immigrants or refugees suffering from post-traumatic stress disorder, adjustment disorder, and other stressrelated conditions. Re-diagnosis from a psychotic to non-psychotic disorder was significantly associated with recent arrival to Canada (odds ratio $[\mathrm{OR}]=6.05,95 \%$ confidence interval $[\mathrm{CI}]=1.56,23.46)$, being nonblack $(\mathrm{OR}=3.72[1.03,13.41])$, and referral from non-medical sources (such as social work or occupational therapy) (OR $=3.23$ $[1.03,10.13])$. The CCS has published a text on cultural consultation which summarizes work with over 400 cases, with data indicating that the use of cultural formulation led to rediagnosis in about $60 \%$ of referrals overall (Kirmayer, Guzder, \& Rousseau, 2014).

Similarly, a group in the Netherlands examined differences in psychotic diagnoses for patients of Moroccan origin using an OCF-inspired interview. Zandi and colleagues (2008) adapted the Comprehensive Assessment of Symptoms and History (CASH) —a semistructured diagnostic interview for evaluating schizophrenia and related disorders (Andreasen, Flaum, \& Arndt, 1992)—into a culturally revised version (CASH-CS) by adding explanatory probes and diagnostic decision rules in order to assess whether presenting symptoms were due to non-psychotic idioms of distress or to psychotic disorder. Agreement on the presence or absence of psychotic disorder in 29 Moroccan-origin patients was calculated separately for each version of the CASH against independent clinical diagnoses according to Moroccan psychiatrists. Correspondence between clinical diagnoses and the CASH-CS (93\% diagnostic agreement; kappa $=.79[S D=.11]$ ) was higher than the CASH (48\%; kappa $=-.49$ [.16]), suggesting that this OCF-based approach increased the validity of a standardized diagnostic instrument (Zandi et al., 2008). In another study of 26 
Dutch and 26 Moroccan patients evaluated 30 months after referral for first-episode psychosis, diagnostic stability with the CASH was high for native Dutch (92\%), but low for Moroccans (27\%), whereas diagnostic stability with the CASH-CS was high for both groups ( $85 \%$ and $81 \%$, respectively) (Zandi et al., 2011). These data suggest that attention to culture can substantially improve diagnostic accuracy and reduce the over-diagnosis of psychosis among ethnocultural minorities: age- and gender-adjusted relative risk for first-episode schizophrenia among Moroccan immigrants compared to native Dutch was 7.8 (4.0-15.2) based on the CASH, but 1.5 (0.5-4.3) based on the CASH-CS (Zandi et al., 2010).

Case series also demonstrate the clinical utility of the OCF. The largest case series comes from Spain (Caballero, 2008): 75 patients were assessed with the OCF by physicians. The Outline was used with people from Spain, Africa, Europe, South America, and Asia, resulting in subjective clinician reports of improved communication, reduced diagnostic and treatment errors, and clarification of cultural aspects of transference and countertransference. The OCF-based assessment also had limitations: clinicians found that it consumed too much time, repeated questions from the standard assessment, lacked guidance on how to elicit cultural information, and did not suggest ways to integrate cultural information within psychiatric formulation. In another case series, an outpatient clinic in Sweden specializing in substance abuse treatment conducted a cultural analysis of 20 consecutively admitted women through the OCF, revealing the centrality in this local context of cultural constructions of gender in patterning drinking behaviors, treatment expectations, and emotional reactions to alcohol consumption (DeMarinis, Scheffel-Birath, $\&$ Hansagi, 2009). A group of cultural psychiatrists and medical anthropologists in the Netherlands (Borra, van Dijk, \& Rohlof, 2002; Rohlof et al., 2009) independently documented improvements in diagnosis using the OCF in 17 patients of Middle Eastern or South Asian origin and two native Dutch patients. They warned against mechanistic application of the OCF without attending to multiple facets of identity, mismatched treatment expectations between patients and clinicians, and the impact of current predicaments that can be confused for enduring cultural traits, such as difficulties navigating refugees' political status. In a study of four Native American children, the OCF clarified the relationship of cultural identity to development across the lifespan, psychosocial environments, and treatment settings, although the OCF needed adaptation for children (Novins et al., 1997). Other case compilations have also documented the OCF's diagnostic utility and improvement of clinical outcomes (Cabal-lero \& Lewis-Fernández, 2008; Group for the Advancement of Psychiatry, 2001; Mezzich \& Caracci, 2008), although systematic research on treatment outcomes is limited.

\section{Revisions to the Content of the OCF Operationalized in the CFI}

This section summarizes work on each OCF domain and its operationalization prior to $D S M-5$ (Table 1). Subsequently, we review implementation questions. Key themes and implications for $D S M-5$ are summarized in Table 3. In line with recent theories on the implementation and dissemination of health interventions (Gearing et al., 2011), we consider implications for DSM-5 unique to the intervention (CFI) separately from the service settings in which the intervention would be implemented. 


\section{Key Themes Related to the CFI as an Intervention}

Cultural Identity of the Individual. Cultural psychiatrists regard understanding a patient's identity as indispensable to evaluation. Early guidelines (Lu et al., 1995) suggested assessing cultural identity through an "interpersonal grid" (p. 483) documenting ethnicity, race, geographical origin, language, acculturation, gender, age, sexual orientation, religious or spiritual beliefs, socioeconomic class, and education. This entails enquiring about these aspects of identity directly, to avoid stereotyping patients or simplifying sociocultural phenomena based on a clinician's determination of the patient's identity (Lewis-Fernández, 1996). Many clinicians advocate for a comprehensive approach that accounts for how a person's cultural identity can change with context (e.g., with family members compared to with strangers from a different ethnicity), including the patient's perception of the clinician's identity (Aggarwal, 2012a; Lim \& Lin, 1996; Starkey et al., 2008; Yilmaz \& Weiss, 2000). Moreover, this assessment should help the clinician consider how identity, distress, stigma, and language influence symptom expression and interpretation (Acharya, 2009).

The need for guidance on exploring identity in the OCF was underscored by the observation that psychiatric trainees felt uncomfortable probing this aspect of a patient's history (Aggarwal \& Rohrbaugh, 2011). Table 1 lists aspects of cultural identity included in various questionnaires, protocols, and interviews that have operationalized the OCF prior to the CFI. Certain aspects were included in nearly all instruments, including: determining the cultural groups with which the patient identifies; establishing the importance and meaning ascribed by the patient and his/her family to this identification; assessing language use, including by developmental period and setting; and determining the patient's involvement with the cultures of origin and settlement for immigrants, including both positive and negative experiences.

Aspects of identity in some instruments whose importance was confirmed by the DSM-5 literature reviews included evaluating experiences of multiple identities and how identity impacts on the clinical problem. Several instruments included a detailed migration history. The Intercultural Interview from the UK guides clinicians to inquire about the origin and meaning of a patient's name and to explore the significance of the clinician's own identity for the patient (Jadhav, 2010a, 2010b). This inter-cultural approach emphasizes the exchange of cultural journeys (e.g., geographic dislocations and cultural displacements) between the clinician and patient. The process aims to promote a more empathic understanding of the patient's identity and a more accurate assessment of psychopathology compared to a standard evaluation (Jadhav et al., 2009).

All of these instruments use open-ended questions to encourage exploration, rather than a checklist for aspects or dimensions of cultural identity. This approach deters the "culturalization" of contextual factors, whereby social processes-such as adverse experiences associated with migration and discrimination—are misunderstood as traits or characteristics of individuals or groups rather than as responses to social contexts or predicaments shaped by social and health institutions (e.g., asylum-seeking process for refugees) (Jenks, 2011; Santiago-Irizarry, 1996). 
Assessment of cultural identity may involve challenges for particular populations. Refugees may be suspicious of questions about identity, and many migrants may not know how to describe or discuss their identities with clinicians unfamiliar with their geographic, political, and historical backgrounds (Rohlof et al., 2009). Children and adolescents may have different identities than their parents depending on mixed parentage, adoption (Novins et al., 1997; Rousseau, Measham, \& Bathiche-Suidan, 2009), and acculturation as a result of migration (Aggarwal, 2010a). The identity of older patients may be shaped by cultural meanings of old age based on social roles and status (Aggarwal, 2010b). Cultural identity should be explored with reference to context, the recognition of multiple strands or hybridity, and the possibility of change over time.

Cultural Explanations of the Individual's IIIness-Patient-centered, ethnographic approaches to history taking guide this research tradition in cultural psychiatry. Medical anthropologists have developed methods for eliciting and analyzing patients' explanatory models of illness, which may include experiences and ideas about onset, causes, mechanisms, course, and treatment expectations (Kleinman, 1980). Efforts to systematize this process include the Explanatory Model Interview Catalogue (EMIC), a research tool that allows both qualitative and quantitative analysis of explanatory model narratives (Weiss, 2001). Although developed as a research instrument, experience with the EMIC has influenced the development of clinical tools, including the Short Explanatory Model Interview (Lloyd et al., 1998).

While Kleinman's initial description of explanatory models emphasized information about causality, mechanisms, and anticipated outcomes, patients' narrations of illness may adopt other forms (Kirmayer, Young, Robbins, 1994). Ethnographic fieldwork has shown that, in addition to everyday explanatory accounts of illness, patients may also use chain complexes or sequences of events that occurred in temporal and spatial proximity (linked by contiguity or metonymy) and illness prototypes, illness episodes that provide examples used to reason about one's experience (Young, 1981, 1982). Patients may think metaphorically without indicating explicit causal models or attributions (Hinton, Franz, Yeo, \& Levkoff, 2005; Jadhav, 2001b; Young, 1981). These findings informed the McGill Illness Narrative Interview (MINI; Groleau et al., 2006), a semi-structured interview designed to obtain illness narratives based on: (a) contiguity of events, (b) cultural prototypes of the illness for the patient, and (c) explanatory models of illness. Attempts to code narratives of people with medically unexplained symptoms in the community elicited by the MINI revealed three types of explanatory narratives: nominal, in which a condition was named without a cause; causal attributions, in which a symptom or illness was linked to a cause; and process or mechanism explanations, in which mechanistic or metaphorical accounts of processes linked cause and symptom (Stern \& Kirmayer, 2004). Illness models also change in response to context, including interviewer and location (Ghane, Kolk, \& Emmelkamp, 2010; Jadhav, 2001b), interactions with family, community, or health care system (Kirmayer \& Sartorius, 2007), during the adaptation or acculturation of immigrants to new cultural contexts (Bhugra, 2004; Karasz, 2005; McCabe \& Priebe, 2004), and even over the span of a long interview, as trust is established and memories are evoked (Groleau \& Kirmayer, 2004). 
Further, culture also influences elicitation of illness models. Cultural norms affect patient communication with providers, family, and friends (Browne, 2001; Dinh \& Groleau, 2008). Eliciting illness representations of the patient's family members, friends, or close associates can clarify the range of views influencing the illness experience (Kirmayer et al., 2014). The organization of health care services may also determine attitudes toward disease, diagnosis, and treatment (Annas \& Miller, 1994; Jadhav \& Barua, 2012).

Eliciting past and current expectations of care are important goals of this OCF section. Cultural schemas or scripts associate illness representations with specific types of selfcoping and help seeking, including the perceived relevance and efficacy of mental health treatments (Al-Krenawi et al., 2009; Kung \& Lu, 2008; Saint-Arnault \& Shimabukuro, 2012). Cultural adaptations of treatment interventions incorporating cultural scripts may enhance patient engagement and outcomes (Griner \& Smith, 2006; Kopelowicz et al., 2012), indicating the value of identifying cultural models and interpretations before treatment (Lewis-Fernández et al., 2013). Non-medical forms of self-coping and help seeking are common and merit clinical attention because they may complement or conflict with psychiatric care (Bhikha, Farooq, Chaudhry, \& Husain, 2012; Brown et al., 2011; Zafar et al., 2008). Barriers to service utilization also reflect cultural priorities for care, family values and interactions, and local health system factors affecting access (Dejman et al., 2008; Jadhav \& Barua, 2012; Knipscheer \& Kleber, 2005).

Earlier OCF guidelines (Lu et al., 1995) included culture-bound syndromes in this section. In $D S M$-5, the term "culture-bound syndrome" has been replaced by three newer terms: cultural syndromes, cultural idioms of distress, and cultural explanations (APA, 2013). These terms denote how cultural modes of expressing or communicating distress may reflect specific symptom clusters (syndromes), common expressions for distress that may not involve specific symptoms (idioms), or involve explicit causal models or attributions. Patient clinical presentations may be influenced by these cultural concepts and modes of expression (Hinton \& Lewis-Fernández, 2010; Kirmayer \& Bhugra, 2009).

Comparing previously developed OCF instruments (Table 1) reveals that all include questions on illness-related idioms, symptom meaning (and usually severity) in relation to cultural norms, causes, expected course of illness, experiences with care, and treatment expectations. Nearly all approaches ask patients to describe the views of others in their social network to situate the patient's perspective in family and community context. Other questions related to illness models and experience highlighted by the literature review include those on how the patient describes the problem to his/her social network, the most troubling aspect of the problem, the contribution of prototypes to the patient's understanding of the illness, the most useful treatment received, the treatment recommendations of the social network, and the patient's use of healers and alternative services.

\section{Cultural Factors Related to Psychosocial Environment and Levels of}

Functioning-The OCF directs clinicians to clarify cultural interpretations of the stressors and supports associated with a patient's illness, and fears and hopes affecting levels of functioning. Instruments (Table 1) have used open-ended questions to obtain a richer picture of these topics. The goal is a description of the context in which the illness emerged and the 
current situation through the perspectives of the patient and others close to him or her. The subjective aspect ("lived experience") of the patient's and social network's response is important because interpretation is strongly influenced by culture and shapes the perceived centrality, magnitude, and tractability of the problem (Bäärnhielm \& Scarpinati Rosso, 2009; Lazarus, 1999) as well as potential supports (Poulin et al., 2012; Snowden, 2007). During assessment, the person's subjective experience is interpreted through the clinician's analysis of the social and cultural context. A subjective-objective approach develops a functional assessment of activities of daily living that includes the interpretations of patients and their social networks in relation to cultural norms of functioning (Qureshi, Collazos, \& Ramos, 2013).

Ethnocultural minorities and racialized groups may face distinctive stressors associated with their social status. Migration status is a potent social determinant of health for refugees independent of pre-migratory trauma (Kirmayer et al., 2011; Porter, 2007; Porter \& Haslam, 2005; Steel et al., 2009). Factors most associated with risk for psychopathology include low socioeconomic status, poor housing, unemployment or under-employment, lack of residency, linguistic barriers, limited social networks, discrimination, role strain, family conflict, status loss, acculturative stress, nostalgia, and bicultural tension (Bhugra, 2004; Finch \& Vega, 2003; Hovey \& Magaña, 2002; Tartakovsky, 2007). Discrimination affects various social groups, such as religious minorities, lesbian-gay-bisexual-transgender persons, and low socicoeconomic status and disability communities (Bogart et al., 2011; McLaughlin, Hatzenbuehler, \& Keyes, 2010; Rousseau et al., 2011), whose subjective experience of stress and coping should be assessed. Specific questions may need adaptation for the discriminated group, social position, and the individual predicament of the patient.

To adequately assess social stressors and supports, an operationalized OCF needs to obtain collateral information from the patient's social network (Mezzich et al., 2009); this is important for all patients but is especially so for children and adolescents (Novins et al., 1997; Rousseau et al., 2009) and older adults (Aggarwal, 2010a; Hinton et al., 2006). Similarly, there is a need for guidance on obtaining information through medical interpreters and culture brokers (Leanza, Miklavcic, Boivin, \& Rosenberg, 2013; Mezzich et al., 2009; Rohlof et al., 2009).

Finally, any assessment of help seeking must consider the fact that patients often turn to religion, spirituality, and moral traditions to understand and respond to mental illness (Whitley, 2012a). There is a "religiosity gap" between clinicians trained in positivistic scientific methods who may disparage religion and patients who search for holistic treatments and are invested in religious beliefs and practices (Lukoff, Turner, \& Lu, 1992). Cultural assessment thus should attend to the meanings associated with religion in illness experience, especially when a religious community provides support (Whitley, 2012b). Such information can help to mobilize support that contributes to recovery.

The existing OCF instruments (Table 1) assess stressors, supports, and levels of functioning in different ways. Alternatives include focusing on the impact of stressors on the patient, the views of the social network, the role of the person's partner and/or of spiritual support, 
barriers to receiving help, and the views of the social network on resulting levels of functioning.

\section{Cultural Elements of the Relationship Between the Individual and the Clinician}

- Many OCF case studies illustrated challenges in providing cross-cultural care. These included tensions between biomedical treatment and other forms of healing (Barrett, 1997), the failure of health systems to provide interpreters (Bucardo, Patterson, \& Jeste, 2008), and difficulties in communication (Yilmaz \& Weiss, 2000). In several studies (Groen, 2009a; Moldavsky, 2003; Shaffer \& Steiner, 2006), clinicians discussed tensions in considering the patient individually and as part of a social group. Despite the clinicians' best efforts, the medical encounter may be influenced by stereotyping, discrimination, racism, and subtle forms of bias (Jadhav, 2001a; Whaley, 2001). This domain of the OCF provides an opportunity to consider how these experiences affect patients' perceptions of care through clinician self-reflection.

Existing instruments address this domain differently (Table 1). Some focus on the clinician, providing queries to consider rather than questions addressed to the patient. The Montreal CCS interview (Kirmayer et al., 2001; Kirmayer, Thombs et al., 2008c) includes questions on the mutual perceptions of power and positioning of the patient and clinician, including historical relations between their respective cultural groups. This operationalizes the concepts of "cultural transference" and "cultural countertransference" to analyze patientphysician relationships (Comas-Díaz \& Jacobsen, 1991; Kir-mayer, Rousseau et al., 2008b; Mezzich et al., 2009). Other instruments suggest questions for the patient, including on the quality of communication, the need for interpreters, topics missed during the interview, the impact of cultural matching with the clinician, and the role of the patient. Although a sensitive topic, open inquiry into negative experiences of care and potential miscommunications early in care (e.g., during intake) may facilitate rapport and engagement because it conveys a commitment to overcome treatment barriers and may allow a corrective experience of "cultural humility" (Tervalon \& Murray-García, 1998).

\section{Key Themes Related to the Implementation of the CFI}

Contexts of Use-Obstacles to wider use of the OCF have included the lack of detail on when, where, and how it should be used, that is, for which patients, for what purposes, by which staff members, and at which point in the course of clinical care (Cuéllar \& Paniagua, 2000). More attention is needed to clarify the role of the OCF in ongoing treatment beyond the initial evaluation (Lewis-Fernández, 2009). Jadhav (2010a, 2010b) recommends using the OCF to engage all patients. Kirmayer and colleagues $(2003,2014)$ advocate its use in specialized clinical consultations for patients where cultural factors are complicating care. Others suggest reserving it for patients whose presentation includes cultural content unfamiliar to the clinician (Caballero, 2009). Whereas most published case studies feature patients from cultural backgrounds unfamiliar to the treating clinician such as immigrants or ethnic minorities, some also include reports of culturally similar patients and clinicians, indicating how the OCF may clarify intra-cultural issues (Aggarwal, 2012a; Rohlof, Groen, van Dijk, \& Starmans, 2010). 
Guidance is also needed on the clinical training and skills needed to conduct cultural assessment and produce a cultural formulation. In most published case reports, the treating clinician was the interviewer. However, the OCF may also be used by adjunctive personnel, such as a culture broker or anthropologist (Dinh \& Groleau, 2008; Groen, 2009a; Kirmayer, Thombs et al., 2008c; Miklavcic \& Leblanc, 2014; Rohlof et al., 2009) to integrate OCF data with routine clinical findings. In Montreal's CCS, the perceived utility of the OCF did not differ between clinicians and non-clinicians (e.g., culture brokers), though psychologists found it more useful than did physicians (Kirmayer, Thombs et al., 2008c). Dinh and colleagues (2012) showed that the OCF changed dynamics of a multidisciplinary group by increasing the participation of non-medical professionals who could contribute to understanding the patient's social world. Assigning this task of cultural assessment to specialized personnel may enhance the cultural information gathered, but deprive treating clinicians of interacting with the patient directly.

Views differ about whether or not OCF-based questions should be integrated into routine clinical assessment. Some authors suggest that the assessing clinician could incorporate portions of the OCF into the clinical evaluation, for example, by including questions in the domain of Cultural Explanations of the Individual's Illness in assessment of the history of present illness (Aggarwal, 2012b; Caballero, 2009; Jadhav, 2010a). This approach may encourage attention to this aspect of the OCF without a full interview for every patient. To ensure comprehensive assessment of complex cases, the McGill CCS conducts a combined clinical-cultural assessment over 1-3 visits that includes the patient as well as key people in his or her social network (Kirmayer et al., 2003). Other clinicians in refugee clinics in Sweden and the Netherlands conduct supplementary interviews after the intake assessment (Bäärnhielm \& Scarpinati Rosso, 2009; Rohlof et al., 2009).

Although cultural formulation is potentially relevant and useful for any patient, the DSM-5 DCCIS identified five main situations when assessment of cultural factors may be especially relevant for patient care: (1) difficulties in diagnostic assessment based on the clinician's unfamiliarity with the patient's culture; (2) uncertainty about how diagnostic criteria fit with the patient's symptoms; (3) difficulties in judging illness severity or impairment; (4) disagreements between the patient and clinician about the course of care; and (5) limited treatment adherence and engagement from the patient (APA, 2013). Future work may identify other situations when the CFI can be useful.

Length and Content-The length of the various OCF interviews, questionnaires, and protocols listed in Table 1 varies from 30 to 90 minutes. The dilemma is how to balance brevity with sufficient depth. Kirmayer, Thombs and colleagues (2008c) found that $27 \%$ of clinicians on the CCS felt the interview failed to assess important information and $30 \%$ found it too lengthy.

The literature is divided on which section(s) could be shortened or eliminated. A study of patients referred for cultural consultation found that the domain of Cultural Explanations of the Individual's Illness contributed less to final formulations than did other domains, perhaps because patients have several concurrent models of illness and are reluctant to offer views that diverge from what they believe the clinician expects (Kirmayer et al., 2003), a finding 
replicated elsewhere (Bäärnhielm \& Scarpinati Rosso, 2009; Groleau et al., 2006).

Nonetheless, in some cases this domain may yield crucial information, and these authors do not recommend eliminating this section. Similarly, Rohlof and colleagues (2009) suggested that the domain of Cultural Elements of the Relationship Between the Individual and the Clinician be subsumed elsewhere. Others supported an elaboration of this section to establish rapport, promote engagement, and uncover information around Cultural Factors Related to Psychosocial Environment and Levels of Functioning, such as discrimination and acculturation (Jadhav, 2010a, 2010b). These differing suggestions may reflect the diverse clinical settings and cultural contexts in which the OCF has been used and suggest the need for flexible application in both the order of presentation and depth of elaboration.

Training-Developing a standard training protocol is a necessary step in the large-scale implementation of any intervention, including assessment interviews like the CFI (Rounsaville, Carroll, \& Onken, 2001). Typically, a training protocol consists of reviewing written guidelines with clinicians and answering any questions, observing the intervention through a video demonstration, and practicing the intervention through case-based simulations (Carroll, Martino, \& Rounsaville, 2010). Live supervision or review of videotaped interviews can be used to ensure that trainees are able to apply the interview protocol as intended. As measurement-based care becomes more widespread, CFI implementation will likely be assessed through instruments that rate fidelity of use after training (Gearing et al., 2011).

The DSM-5 CFI has several of the components needed to develop a standard training protocol. The sample interview questions are accompanied by guidelines indicating the rationale and goal for each item that can be reviewed by clinicians. Case simulations like those developed for the DSM-5 field trial of the CFI can be prepared for trainees, with examples chosen to reflect the types of setting in which they work. A training video (in collaboration with the New York State public mental health system) and a handbook for the use of the CFI are currently in preparation and will include video vignettes illustrating application of the interview. The Psychiatry Milestone Project, a joint endeavor from the Accreditation Council for Graduate Medical Education (ACGME) and the American Board of Psychiatry and Neurology, requires psychiatry residents to evaluate cultural factors in psychiatric formulation and differential diagnosis, patient development across the lifespan, knowledge of psychopathology, and clinical ethics (ACGME, 2013). The CFI may address these needs, though future work could investigate the reception of CFI training by residency directors, course leaders, and trainees; the challenges of including the CFI within the curriculum; and the extent to which trainees use the CFI after graduation. The development of training videos and evaluation materials would help residency directors and service administrators assess clinician skill in using the CFI (Aggarwal et al., in press). Training models in cultural psychiatry aimed at medical students and residents illustrate how to teach the OCF, including didactic review and journal club discussion of OCF domains, case illustration by preceptors, and supervised case formulation and class presentations by trainees. These approaches are sometimes combined with experiential learning (e.g., community visits), cultural self-reflection exercises, and basic ethnographic techniques (e.g., simple field notes), especially by preceptors cross-trained in the social sciences (Hansen et 
al., 2013; Kirmayer, Rousseau et al., 2008a; Kirmayer et al., 2012). These OCF-focused methods may help guide CFI training.

\section{CONCLUSION}

With the development of the CFI, DSM-5 has greatly expanded the considerations of culture and context introduced in DSM-IV. The Outline for Cultural Formulation in DSM-IV generated substantial international interest as a potential way of improving the cultural validity of diagnosis and treatment planning. Experience with the OCF guided development of the semi-structured CFI, which was tested in an APA-supported field trial at 12 clinical sites in six countries. The literature reviews conducted for $D S M-5$ and the experience of the DSM-5 Cross-Cultural Issues Subgroup supported the value of the OCF framework and guided the design of the CFI as a tool for facilitating cultural aspects of assessment and treatment planning in clinical practice.

By providing a clear and concise approach to cultural assessment and treatment planning, the CFI will allow us to address some basic questions in psychiatry. To what extent does a culturally oriented interview change important aspects of care, including diagnosis, treatment planning, and patient satisfaction and adherence? Can patient engagement be enhanced through personalized forms of clinical negotiation and exchange of clinicianpatient perspectives through the CFI? Does a brief standardized interview such as the core CFI actually help clinicians assess culture and context? Will the telescoping structure of the DSM-5 core CFI, informant version, and supplementary modules enable clinicians to choose the desired level of assessment for each clinical situation? Will a set of interviews facilitate dissemination and implementation of cultural assessment and treatment planning beyond what was achieved with the DSM-IV Outline for Cultural Formulation? We hope that research and clinical experience with the CFI will answer many of these questions in the years to come.

\section{REFERENCES}

Accreditation Council for Graduate Medical Education. The psychiatry milestone project. 2013. Accessed from https://www.acgme.org/acgmeweb/tabid/147/ProgramandInstitutionalAccreditation/ MedicalSpecialties/Psychiatry.aspx

Acharya L. Bhutanese refugees 15 years later: A study on the effects of trauma among women who are survivors of torture (Doctoral dissertation, Massachusetts School of Professional Psychology). ProQuest Dissertations \& Theses (PQDT). 2009:304815643.

Adeponle AB, Thombs BD, Groleau D, Jarvis E, Kirmayer LJ. Using the cultural formulation to resolve uncertainty in diag noses of psychosis among ethnoculturally diverse patients. Psychiatric Services. 2012; 63:147-153. [PubMed: 22302332]

Aggarwal NK. Cultural formulations in child and adolescent psychiatry. Journal of the American Academy of Child and Adolescent Psychiatry. 2010a; 49:306-309. [PubMed: 20410723]

Aggarwal NK. Reassessing cultural evaluations in geriatrics: Insights from cultural psychiatry. Journal of the American Geriatrics Society. 2010b; 58:2191-2196. [PubMed: 20977437]

Aggarwal NK. Hybridity and intersubjectivity in the clinical encounter: Impact on the Cultural Formulation. Transcultural Psychiatry. 2012a; 49:121-139. [PubMed: 22218399]

Aggarwal NK. Adapting the cultural formulation for clinical assessments in forensic psychiatry. Journal of the American Academy of Psychiatry and the Law. 2012b; 40:113-118. [PubMed: 22396348] 
Aggarwal NK, Glass A, Tirado A, Boiler M, Nicasio A, Alegría M, Wall M, Lewis-Fernández R. The development of the Cultural Formulation Interview-Fidelity Instrument (CFI-FI): A pilot study. Journal of Health Care for the Poor and Underserved. in press.

Aggarwal NK, Rohrbaugh RM. Teaching cultural competency through an experiential seminar on anthropology and psychiatry. Academic Psychiatry. 2011; 35:331-334. [PubMed: 22007094]

Alarcón RD. Culture, cultural factors and psychiatric diagnosis: Review and projections. World Psychiatry. 2009; 8:131-139. [PubMed: 19812742]

Al-Krenawi A, Graham JR, Al-Bedah EA, Kadri HM, Sehwail MA. Cross-national comparison of Middle Eastern university students: Help-seeking behaviors, attitudes toward helping professionals, and cultural beliefs about mental health problems. Community Mental Health Journal. 2009; 45:26-36. [PubMed: 19067161]

American Psychiatric Association. Diagnostic and statistical manual of mental disorders. 4th ed.. Author; Arlington, VA: 1994.

American Psychiatric Association. Diagnostic and statistical manual of mental disorders. 4th ed., text rev.. Author; Arlington,VA: 2000.

American Psychiatric Association. Diagnostic and statistical manual of mental disorders. 5th ed.. Author; Arlington, VA: 2013.

Andreasen NC, Flaum M, Arndt S. The comprehensive assessment of symptoms and history (CASH): An instrument for assessing diagnosis and psychopathology. Archives of General Psychiatry. 1992; 49:615-623. [PubMed: 1637251]

Annas GJ, Miller FH. The empire of death: How culture and economics affect informed consent in the U.S., the U.K., and Japan. American Journal of Law and Medicine. 1994; 20:357-394. [PubMed: 7618635]

Bäärnhielm, S.; Gustafsson, C. En utbildarhandledning [Training about culture and context in psychiatric diagnosis: A training guide]. Transkulturellt Centrum; Stockholm, Sweden: 2010. Att utbilda om kultur och kontext vid psykiatrisk di agnostik och bedömning..

Bäärnhielm S, Scarpinati Rosso M. The Cultural Formulation: A model to combine nosology and patients' life context in psychiatric diagnostic practice. Transcultural Psychiatry. 2009; 46:406428. [PubMed: 19837779]

Bäärnhielm, S.; Scarpinati Rosso, M.; Pattyi, L. Manual för intervju enligt kulturformuleringen i DSM-IV [Culture, context and psychiatric diagnosis: Interview manual according to DSM-IV]. Transkulturellt Centrum; Stockholm, Sweden: 2007. Kultur, kontext och psykiatrisk diagnostik..

Bäärnhielm, S.; Scarpinati Rosso, M.; Pattyi, L. Manual for diagnostisk intervju baseret på kulturformuleringen fra DSM-IV [Culture, context, and psychiatric diagnosis: Interview manual according to DSM-IV]. NAKMI (National kompetanseenhet for minoritetshelse), Norsk psykiatrisk forening, den Norske legerforening och Norsk psykologforening; Oslo, Norway: 2010. Kultur, kontekst og psykopatologi..

Barrett RJ. Sakit Gila in an Iban long-house: Chronic schizophrenia. Culture, Medicine and Psychiatry. 1997; 21:365-379.

Beijers, H.; van Dijk, R. De implementatie van het Culturele Interview [Implementing the Cultural Interview].. In: van Dijk, R.; Beijers, H.; Groen, S., editors. Het Culturele Interview: In gesprek met de hulpvrager over cultuur en context [The Cultural Interview: Discussing culture and context with patients]. Pharos; Utrecht, The Netherlands: 2012. p. 196-209.

Bhikha AG, Farooq S, Chaudhry N, Husain N. A systematic review of explanatory models of illness for psychosis in developing countries. International Review of Psychiatry. 2012; 24:450-462. [PubMed: 23057981]

Bhugra D. Migration and mental health. Acta Psychiatrica Scandinavica. 2004; 109:243-258. [PubMed: 15008797]

Bogart LM, Wagner GJ, Galvan FH, Landrine H, Klein DJ, Sticklor LA. Perceived discrimination and mental health symptoms among Black men with HIV. Cultural Diversity \& Ethnic Minority Psychology. 2011; 17:295-302. [PubMed: 21787061]

Borra, R.; van Dijk, R.; Rohlof, H. Cultuur, Classificatie en Diagnose: Cultuursensitief Werken met de DSM-IV [Culture, classification and diagnosis: Applying DSM-IV in a culturally sensitive way]. Bohn Stafleu van Loghum; Houten, The Netherlands: 2002. 
Brown JS, Casey SJ, Bishop AJ, Prytys M, Whittinger N, Weinman J. How black African and white British women perceive depression and help-seeking: A pilot vignette study. International Journal of Social Psychiatry. 2011; 57:362-374. [PubMed: 20197456]

Browne KO. Cultural formulation of psychiatric diagnoses. Sakit Jiwa, $\mathrm{Ng}$ (amuk), and schizoaffective disorder in a Javanese woman. Culture, Medicine and Psychiatry. 2001; 25:411-425.

Bucardo JA, Patterson TL, Jeste DV. Cultural formulation with attention to language and cultural dynamics in a Mexican psychiatric patient treated in San Diego, California. Culture. Medicine and Psychiatry. 2008; 32:102-121.

Caballero, L. Formulación cultural de casos psiquiátricos DSM-IV-TR [DSM-IV-TR cultural formulation of psychiatric cases].. In: Martínez, LC.; Lewis-Fernández, R., editors. Formulación y abordaje cultural de casos psiquiátricos [Formulation and management of psychiatric cases. Luzán; Madrid, Spain: 2008. p. 11-34.

Caballero L. DSM-IV-TR cultural formulation of psychiatric cases: Two proposals for clinicians. Transcultural Psychiatry. 2009; 46:506-523. [PubMed: 19837784]

Caballero, L.; Lewis-Fernández, R. Formulación y abordaje cultural de casos psiquiátricos [Formulation and management of psychiatric cases]. Luzán; Madrid, Spain: 2008.

Carroll KM, Martino S, Rounsaville BJ. No train, no gain? Clinical Psychology: Science and Practice. 2010; 17:36-40.

Comas-Díaz L, Jacobsen F. Ethnocultural transference and countertransference in the therapeutic dyad. American Journal of Orthopsychiatry. 1991; 61:392-402. [PubMed: 1951646]

Cuéllar, I.; Paniagua, FA. Handbook of multicultural mental health: Assessment and treatment of diverse populations. Academic Press; Orlando, FL: 2000.

Dejman M, Ekblad S, Forouzan AS, Baradaran-Eftekhari M, Malekafzali H. Explanatory model of help-seeking and coping mechanisms among depressed women in three ethnic groups of Fars, Kurdish, and Turkish in Iran. Archives of Iranian Medicine. 2008; 11:397-406. [PubMed: 18588372]

DeMarinis V, Scheffel-Birath C, Hansagi H. Cultural analysis as a perspective for gender-informed alcohol treatment research in a Swedish context. Alcohol \& Alcoholism. 2009; 44:615-619. [PubMed: 19047017]

Dinh NM, Groleau D. Traumatic amputation: A case of Laotian indignation and injustice. Culture, Medicine and Psychiatry. 2008; 32:440-457.

Dinh NM, Groleau D, Kirmayer LJ, Rodriguez C, Bibeau G. Influence of the DSM-IV Outline for Cultural Formulation on multidisciplinary case conferences in mental health. Anthropology \& Medicine. 2012; 19:261-276. [PubMed: 22309357]

Finch BK, Vega WA. Acculturation stress, social support, and self-rated health among Latinos in California. Journal of Immigrant Health. 2003; 5:109-117. [PubMed: 14512765]

Fung K, Andermann L, Zaretsky A, Lo HT. An integrative approach to cultural competence in the psychiatric curriculum. Academic Psychiatry. 2008; 32:272-282. [PubMed: 18695028]

Gearing RE, El-Bassel N, Ghesquiere A, Baldwin S, Gillies J, Ngeow E. Major ingredients of fidelity: A review and scientific guide to improving quality of intervention research implementation. Clinical Psychology Review. 2011; 31:79-88. [PubMed: 21130938]

Ghane S, Kolk AM, Emmelkamp PM. Assessment of explanatory models of mental illness: Effects of patient and interviewer characteristics. Social Psychiatry and Psychiatric Epidemiology. 2010; 45:175-182. [PubMed: 19381425]

Griner D, Smith T. Culturally adapted mental health interventions: A meta-analytic review. Psychotherapy. 2006; 43:531-538. [PubMed: 22122142]

Groen S. Recognizing cultural identity in mental health care: Rethinking the cultural formulation of a Somali patient. Transcultural Psychiatry. 2009a; 46:451-462. [PubMed: 19837781]

Groen, S. Brief Cultural Interview 2009 (BCI-2009). 2009b. Available at: http://www.mcgill.ca/ iccc/ sites/mcgill.ca.icc/files/Interview.pdf

Groleau D, Kirmayer LJ. Sociosomatic theory in Vietnamese immigrants' narratives of distress. Anthropology \& Medicine. 2004; 11:117-133. 
Groleau D, Young A, Kirmayer LJ. The McGill Illness Narrative Interview (MINI): An interview schedule to elicit meanings and modes of reasoning related to illness experience. Transcultural Psychiatry. 2006; 43:671-691. [PubMed: 17166953]

Group for the Advancement of Psychiatry. Cultural assessment in clinical psychiatry. American Psychiatric Publishing; Washington, DC: 2001.

Hansen H, Dugan TM, Becker AE, Lewis-Fernández R, Lu FG, Oquendo MA, Trujillo M. Educating psychiatry residents about cultural aspects of care: A qualitative study of approaches used by U.S. expert faculty. Academic Psychiatry. 2013; 37:412-416. [PubMed: 24185288]

Harris TL, McQuery J, Raab B, Elmore S. Multicultural psychiatric education: Using the DSM-IV-TR Outline for Cultural Formulation to improve resident cultural competence. Academic Psychiatry. 2008; 32:306-312. [PubMed: 18695032]

Hinton, L.; Flores, Y.; Franz, C.; Hernández, I.; Mitteness, L. The borderlands of primary care: Family and primary care physician perspectives on "troublesome" behaviors of people with dementia.. In: Liebling, A.; Cohen, L., editors. Thinking about dementia; Culture, loss, and the anthropology of senility. Rutgers University Press; New Brunswick, NJ: 2006. p. 43-63.

Hinton L, Franz C, Yeo G, Levkoff S. Conceptions of dementia in a multi-ethnic sample of family caregivers. Journal of the American Geriatric Society. 2005; 53:1405-1410.

Hinton DE, Lewis-Fernández R. Idioms of distress among trauma survivors: Sub-types and clinical utility. Culture, Medicine and Psychiatry. 2010; 34:209-218.

Hovey JD, Magaña CG. Psychosocial predictors of anxiety among immigrant Mexican migrant farmworkers: Implications for prevention and treatment. Cultural Diversity and Ethnic Minority Psychology. 2002; 8:274-289. [PubMed: 12143104]

Jadhav, S. Community psychiatry and clinical anthropology.. In: Yilmaz, AT.; Reicher-Rossler, A.; Weiss, M., editors. Cultural psychiatry: Euro-international perspectives. Karger; Basel, Switzerland: 2001a. p. 141-154.

Jadhav S. Cultural experience of depression among white Britons in London. Anthropology and Medicine. 2001b; 8:47-69.

Jadhav, S. Testing the clinical efficacy of Cultural Formulations in acute mental health: A randomized controlled trial (UKCRN ID 5251). National Forensic Mental Health R\&D Programme; London: 2010a.

Jadhav, S. The Bloomsbury Cultural Formulation Interview [motion picture]. University College London; London: 2010b. Available at: http://www.ucl.ac.uk/ccs/specialist-services/\#bcflightbox

Jadhav S, Barua M. The implications of human-elephant conflict on peoples' mental well-being. Health and Place. 2012; 18:1356-1365. [PubMed: 22819603]

Jadhav, S.; Jain, S. Clinical appeal of cultural formulations in rural mental health.. In: Chavan, BS.; Gupta, N.; Arun, P.; Sidana, AK.; Jadhav, S., editors. Comprehensive textbook on community psychiatry in India. Jaypee Brothers; Delhi, India: 2012. p. 560-565.

Jadhav, S.; Sengupta, S.; Derges, J.; Littlewood, R.; Stevens, S. Clinical efficacy of cultural formulations in an acute mental health setting: A randomized clinical intervention trial and hospital ethnography.. Research Panel, Annual Meeting of the Society for the Study of Psychiatry \& Culture; 2009.

Jenks AC. From "list of traits" to "open-mindedness": Emerging issues in cultural competence education. Culture, Medicine, and Psychiatry. 2011; 35:209-235.

Karasz A. Cultural differences in conceptual models of depression. Social Science and Medicine. 2005; 60:1625-1635. [PubMed: 15652693]

Kirmayer LJ. Beyond the "new cross-cultural psychiatry": Cultural biology, discursive psychology and the ironies of globalization. Transcultural Psychiatry. 2006; 43:126-144. [PubMed: 16671396]

Kirmayer LJ, Ban L, Fauras V, Adeponle A. Illness explanations in the cultural formulation. 2014 Manuscript submitted for publication.

Kirmayer, LJ.; Bhugra, D. Culture and mental illness: Social context and explanatory models.. In: Salloum, IM.; Mezzich, JE., editors. Psychiatric diagnosis: Patterns and prospects. Wiley; New York, NY: 2009. p. 29-37. 
Kirmayer LJ, Fung K, Rousseau C, Lo HT, Menzies P, Guzder J, Ganesan S, Ander-mann L, McKenzie K. Guidelines for training in cultural psychiatry. Canadian Journal of Psychiatry. 2012; 57:1-17.

Kirmayer LJ, Groleau D, Guzder J, Blake C, Jarvis E. Cultural consultation: A model of mental health service for multicultural societies. Canadian Journal of Psychiatry. 2003; 48:145-153.

Kirmayer, LJ.; Guzder, J.; Rousseau, C., editors. Cultural consultation: Encountering the other in mental health care. Springer; New York, NY: 2014.

Kirmayer LJ, Narasiah L, Muñoz M, Rashid M, Ryder A, Guzder J, Rousseau C. Common mental health problems in immigrants and refugees: General approach to the patient in primary care. Canadian Medical Association Journal. 2011; 183:E959-967. [PubMed: 20603342]

Kirmayer LJ, Rousseau C, Guzder J, Jarvis EG. Training clinicians in cultural psychiatry: A Canadian perspective. Academic Psychiatry. 2008a; 32:313-319. [PubMed: 18695033]

Kirmayer, LJ.; Rousseau, C.; Jarvis, EG.; Guzder, J. The cultural context of clinical assessment.. In: Tasman, A.; Kay, J.; Lieberman, JA.; First, MB.; Maj, M., editors. Psychiatry. John Wiley; Chichester, England: 2008b. p. 54-66.

Kirmayer, LJ.; Rousseau, C.; Rosenberg, E.; Clarke, H.; Saucier, JF.; Sterlin, C.; Latimer, E. Development and evaluation of a cultural consultation service in mental health. Culture \& Mental Health Research Unit, Institute of Community \& Family Psychiatry, Sir Mortimer B. Davis-Jewish Hospital; Montreal Canada: 2001. Available from http://www.mcgill.ca/iccc/resources/cf

Kirmayer LJ, Sartorius N. Cultural models and somatic syndromes. Psychosomatic Medicine. 2007; 69:832-840. [PubMed: 18040090]

Kirmayer LJ, Thombs BD, Jurcik T, Jarvis GE, Guzder J. Use of an expanded version of the DSM-IV outline for cultural formu lation on a cultural consultation service. Psychiatric Services. 2008c; 59:683-686. [PubMed: 18511590]

Kirmayer LJ, Young A, Robbins JM. Symptom attribution in cultural perspective. Canadian Journal of Psychiatry. 1994; 39:584-595.

Kleinman A. Depression, somatization and the "new cross-cultural psychiatry.". Social Science \& Medicine. 1977; 11:3-10. [PubMed: 887955]

Kleinman, A. Patients and healers in the context of culture: An exploration of the borderland between anthropology, medicine, and psychiatry. University of California Press; Berkeley, CA: 1980.

Kleinman A. Anthropology and psychiatry. The role of culture in cross-cultural research on illness. British Journal of Psychiatry. 1987; 151:447-454. [PubMed: 3447661]

Kleinman, A. The illness narratives: Suffering, healing, and the human condition. Basic Books; New York, NY: 1988.

Kleinman A, Benson P. Anthropology in the clinic: The problem of cultural competency and how to fix it. PLoS Medicine. 2006; 3:e294. [PubMed: 17076546]

Knipscheer JW, Kleber RJ. Help-seeking behaviour regarding mental health problems of Mediterranean migrants in the Netherlands: Familiarity with care, consultation attitude and use of services. International Journal of Social Psychiatry. 2005; 51:372-382. [PubMed: 16400912]

Kopelowicz A, Zarate R, Wallace CJ, Liberman RP, Lopez SR, Mintz J. Treatment adherence in Mexican Americans with schizophrenia. Archives of General Psychiatry. 2012; 69:265-273. [PubMed: 22393219]

Kung WW, Lu PC. How symptom manifestations affect help seeking for mental health problems among Chinese Americans. Journal of Nervous and Mental Disease. 2008; 196:46-54. [PubMed: 18195641]

Lazarus, RS. Stress and emotion: A new synthesis. Springer; New York, NY: 1999.

Leanza, Y.; Miklavcic, A.; Boivin, I.; Rosenberg, E. Working with interpreters.. In: Kirmayer, LJ.; Guzder, J.; Rousseau, C., editors. Cultural consultation: Encountering the other in mental health care. Springer SBM; New York, NY: 2014. p. 89-114.

Lewis-Fernández R. Cultural formulation of psychiatric diagnosis. Culture, Medicine and Psychiatry. 1996; 20:133-144.

Lewis-Fernández R. The cultural formulation. Transcultural Psychiatry. 2009; 46:379-382. [PubMed: 19837777] 
Lewis-Fernández R, Balán IC, Patel SR, Sánchez-Lacay AJ, Alfonso C, Gorritz M, Blanco C, Schmidt A, Jiang H, Schneier F, Moyers TB. Impact of motivational pharmacotherapy on treatment retention among depressed Latinos. Psychiatry. 2013; 76:210-222. [PubMed: 23965261]

Lewis-Fernández R, Díaz N. The cultural formulation: A method for assessing cultural factors affecting the clinical encounter. Psychiatric Quarterly. 2002; 73:271-295. [PubMed: 12418357]

Lim, RF. Clinical manual of cultural psychiatry. American Psychiatric Publishing; Washington, DC: 2006.

Lim RF, Diamond RJ, Chang JB, Primm AB, Lu FG. Using non-feature films to teach diversity, cultural competence, and the DSM-IV-TR Outline for Cultural Formulation. Academic Psychiatry. 2008a; 32:291-298. [PubMed: 18695030]

Lim RF, Lin KM. Cultural formulation of psychiatric diagnosis: Case No. 03: Psychosis following Qigong in a Chinese immigrant. Culture, Medicine and Psychiatry. 1996; 20:369-378.

Lim RF, Luo JS, Suo S, Hales RE. Diversity initiatives in academic psychiatry: Applying cultural competence. Academic Psychiatry. 2008b; 32:283-290. [PubMed: 18695029]

Lloyd KR, Jacob KS, Patel V, St. Louis L, Bhugra D, Mann AH. The development of the Short Explanatory Model Interview (SEMI) and its use among primary-care attenders with common mental disorders. Psychological Medicine. 1998; 28:1231-1237. [PubMed: 9794030]

Lu, FG.; Lim, RF.; Mezzich, JE. Issues in the assessment and diagnosis of culturally diverse individuals.. In: Oldham, JM.; Riba, MB., editors. Review of psychiatry, volume 14: Assessment and diagnosis. American Psychiatric Press; Washington, DC: 1995. p. 477-510.

Lukoff D, Turner R, Lu F. Transpersonal psychology research review: Psychoreligious dimensions of healing. Journal of Transpersonal Psychology. 1992; 24:41-60.

McCabe R, Priebe S. Explanatory models of illness in schizophrenia: Comparison of four ethnic groups. British Journal of Psychiatry. 2004; 185:25-30. [PubMed: 15231552]

McLaughlin KA, Hatzenbuehler ML, Keyes KM. Responses to discrimination and psychiatric disorders among Black, Hispanic, female, and lesbian, gay, and bisexual individuals. American Journal of Public Health. 2010; 100:1477-1484. [PubMed: 20558791]

Mezzich JE. Cultural formulation and comprehensive diagnosis: Clinical and research perspectives. Psychiatric Clinics of North America. 1995; 18:649-687. [PubMed: 8545273]

Mezzich, JE. Cultural formulation: Development and critical review.. In: Mezzich, JE.; Caracci, G., editors. Cultural formulation: A reader for psychiatric diagnosis. Aronson; Lanham, MD: 2008. p. 87-92.

Mezzich, JE.; Caracci, G. Cultural formulation: A reader for psychiatric diagnosis. Jason Aronson; Lanham, MD: 2008.

Mezzich JE, Caracci G, Fábrega H, Kir-mayer LJ. Cultural formulation guidelines. Transcultural Psychiatry. 2009; 46:383-405. [PubMed: 19837778]

Mezzich JE, Kirmayer LJ, Kleinman A, Fábrega H, Parron DL, Good BJ, Lin KM, Manson SM. The place of culture in DSM-IV. Journal of Nervous and Mental Disease. 1999; 187:457-464. [PubMed: 10463062]

Miklavcic, A.; Leblanc, MN. Culture brokers, clinically applied ethnography, and cultural mediation.. In: Kirmayer, LJ.; Guzder, J.; Rousseau, C., editors. Cultural consultation: Encountering the other in mental health care. Springer SBM; New York, NY: 2014. p. 115-137.

Moldavsky D. The implication of trans-cultural psychiatry for clinical practice. Israel Journal of Psychiatry and Related Sciences. 2003; 40:47-56. [PubMed: 12817669]

Novins DK, Bechtold DW, Sack WH, Thompson J, Carter DR, Manson SM. The DSM-IV Outline for Cultural Formulation: A critical demonstration with American Indian children. Journal of the American Academy of Child and Adolescent Psychiatry. 1997; 36:1244-1251. [PubMed: 9291726]

Østerskov, M. Kulturel spørgeguide [Cultural Interview Guide]. Videnscenter for Transkulturel Psykiatri; Copenhagen, Denmark: 2011.

Porter M. Global evidence for a biopsy-chosocial understanding of refugee adaptation. Transcultural Psychiatry. 2007; 44:418-439. [PubMed: 17938154] 
Porter M, Haslam N. Predisplacement and postdisplacement factors associated with mental health of refugees and internally displaced persons: A meta-analysis. Journal of the American Medical Association. 2005; 294:602-612. [PubMed: 16077055]

Poulin J, Deng R, Ingersoll TS, Witt H, Swain M. Perceived family and friend support and the psychological well-being of American and Chinese elderly persons. Journal of Cross-Cultural Gerontology. 2012; 27:305-317. [PubMed: 22903533]

Qureshi A, Collazos F, Ramos M. Update on Part C of the Cultural formulation: From concrete to specific and incorporating migration and acculturative stress. 2013 Manuscript in preparation.

Rohlof, H. The cultural interview in the Netherlands: The Cultural Formulation in your pocket.. In: Mezzich, JE.; Caracci, G., editors. Cultural formulation: A reader for psychiatric diagnosis. Aronson; Lanham, MD: 2008. p. 203-213.

Rohlof H, Groen S, van Dijk R, Starmans R. Onderzoek en implementatie van een cultuursensitief instrument [Cultural formulation of diagnosis]. Cultuur, Migratie, Gezondheid. 2010; 7:76-87.

Rohlof H, Knipscheer JW, Kleber RJ. Use of the Cultural Formulation with refugees. Transcultural Psychiatry. 2009; 46:487-505. [PubMed: 19837783]

Rohlof, H.; Loevy, H.; Sassen, L.; Hehnich, S. The cultural interview.. In: Borra, R.; van Dijk, R.; Rohlof, H., editors. Cultuur, classificatie en diagnose: Cultuursensitief werken met DSM-IV [Culture, classification and diagnosis: Applying DSM-IV in a culturally sensitive way. Bohn Stafleu van Loghum; Houten, The Netherlands: 2002. p. 251-260.

Rounsaville BJ, Carroll KM, Onken LS. A stage model of behavioral therapies research: Getting started and moving on from Stage I. Clinical Psychology: Science and Practice. 2001; 8:133-142.

Rousseau C, Hassan G, Moreau N, Thombs BD. Perceived discrimination and its association with psychological distress among newly arrived immigrants before and after September 11, 2001. American Journal of Public Health. 2011; 101:909-915. [PubMed: 20724695]

Rousseau C, Measham T, Bathiche-Suidan M. DSM-IV, culture and child psychiatry. Journal of the Canadian Academy of Child and Adolescent Psychiatry. 2009; 17:69-75. [PubMed: 18516309]

Saint Arnault D, Shimabukuro S. The Clinical Ethnographic Interview: A user-friendly guide to the cultural formulation of distress and help seeking. Transcultural Psychiatry. 2012; 49:302-322. [PubMed: 22194348]

Santiago-Irizarry V. Culture as cure. Cultural Anthropology. 1996; 11:3-24.

Scarpinati Rosso M, Bäärnhielm S. The use of Cultural Formulation in Stockholm: A qualitative study on mental illness experience among migrants. Transcultural Psychiatry. 2012; 49:283-301. [PubMed: 22508638]

Shaffer TG, Steiner H. An application of DSM-IV's outline for cultural formulation: Understanding conduct disorder in Latino adolescents. Aggression and Violent Behavior. 2006; 11:655-663.

Snowden LR. Explaining mental health treatment disparities: Ethnic and cultural differences in family involvement. Culture, Medicine, and Psychiatry. 2007; 31:389-402.

Starkey MT, Lee HK, Tu C-C, Netland J, Goh M, Schuchman DM, Yusuf A. "Only Allah can heal": A cultural formulation of the psychological, religious, and cultural experiences of a Somali man. Journal of Muslim Mental Health. 2008; 3:145-153.

Steel Z, Chey T, Silove D, Marnane C, Bryant RA, van Ommeren M. Association of torture and other potentially traumatic events with mental health outcomes among populations exposed to mass conflict and displacement: A systematic review and meta-analysis. Journal of the American Medical Association. 2009; 302:537-549. [PubMed: 19654388]

Stern L, Kirmayer LJ. Knowledge structures in illness narratives: Development and reliability of a coding scheme. Transcultural Psychiatry. 2004; 41:130-142. [PubMed: 15171211]

Takeshita, J.; Ahmed, I. Culture and aging.. In: Tseng, WS.; Streltzer, J., editors. Cultural competence in clinical psychiatry. American Psychiatric Publishing; Arlington, VA: 2004. p. 147-161.

Tartakovsky E. A longitudinal study of acculturative stress and homesickness: High-school adolescents immigrating from Russia and Ukraine to Israel without parents. Social Psychiatry and Psychiatric Epidemiology. 2007; 42:485-494. [PubMed: 17502976]

Tervalon M, Murray-García J. Cultural humility versus cultural competence: A critical distinction in defining physician training outcomes in multicultural education. Journal of Health Care for the Poor and Underserved. 1998; 9:117-125. [PubMed: 10073197] 
Ton, H.; Lim, RF. The assessment of culturally diverse individuals.. In: Lim, RF., editor. Clinical manual of cultural psychiatry. American Psychiatric Publishing; Arlington, VA: 2006. p. 3-31.

van Dijk R, Beijers H, Groen S. Het Culturele Interview [The Cultural Interview]. Utrecht, The Netherlands: Pharos. 2012

Weiss MG. Cultural epidemiology: An introduction and overview. Anthropology \& Medicine. 2001; 8:5-29.

Whaley AL. Cultural mistrust of white mental health clinicians among African Americans with severe mental illness. American Journal of Orthopsychiatry. 2001; 71:252-256. [PubMed: 11347366]

Whitley R. "Thank you God": Religion and recovery from dual diagnosis among low-income African Americans. Transcultural Psychiatry. 2012a; 49:87-104. [PubMed: 22194344]

Whitley R. Religious competence as cultural competence. Transcultural Psychiatry. 2012b; 49:245260. [PubMed: 22421686]

Yilmaz AT, Weiss MG. Cultural formulation: Depression and back pain in a young male Turkish immigrant in Basel, Switzerland. Culture, Medicine and Psychiatry. 2000; 24:259-272.

Young A. When rational men fall sick: An inquiry into some assumptions made by medical anthropologists. Culture, Medicine and Psychiatry. 1981; 5:317-335.

Young A. Rational men and the explanatory model approach. Culture, Medicine and Psychiatry. 1982; 6:57-71.

Zafar SN, Syed R, Tehseen S, Gowani SA, Waqar S, Zubair A, Yousaf W, Zubairi AJ, Naqvi H. Perceptions about the cause of schizophrenia and the subsequent help-seeking behavior in a Pakistani population: Results of a cross-sectional survey. BMC Psychiatry. 2008; 8:56. [PubMed: 18637176]

Zandi T, Havenaar JM, Laan W, Kahn RS, van den Brink W. Predictive validity of a culturally informed diagnosis of schizophrenia: A 30-month follow-up study with first episode psychosis. Schizophrenia Research. 2011; 133:29-35. [PubMed: 22019074]

Zandi T, Havenaar JM, Limburg-Okken AG, van Es H, Sidali S, Kadri N, van den Brink W, Kahn RS. The need for culture sensitive diagnostic procedures: A study among psychotic patients in Morocco. Social Psychiatry and Psychiatric Epidemiology. 2008; 43:244-250. [PubMed: 18060339]

Zandi T, Havenaar JM, Smits M, Limburg-Okken AG, van Es H, Cahn W, Algra A, Kahn RS, van den Brink W. First contact incidence of psychotic disorders among native Dutch and Moroccan immigrants in the Netherlands: Influence of diagnostic bias. Schizophrenia Research. 2010; 119:27-33. [PubMed: 20332065] 

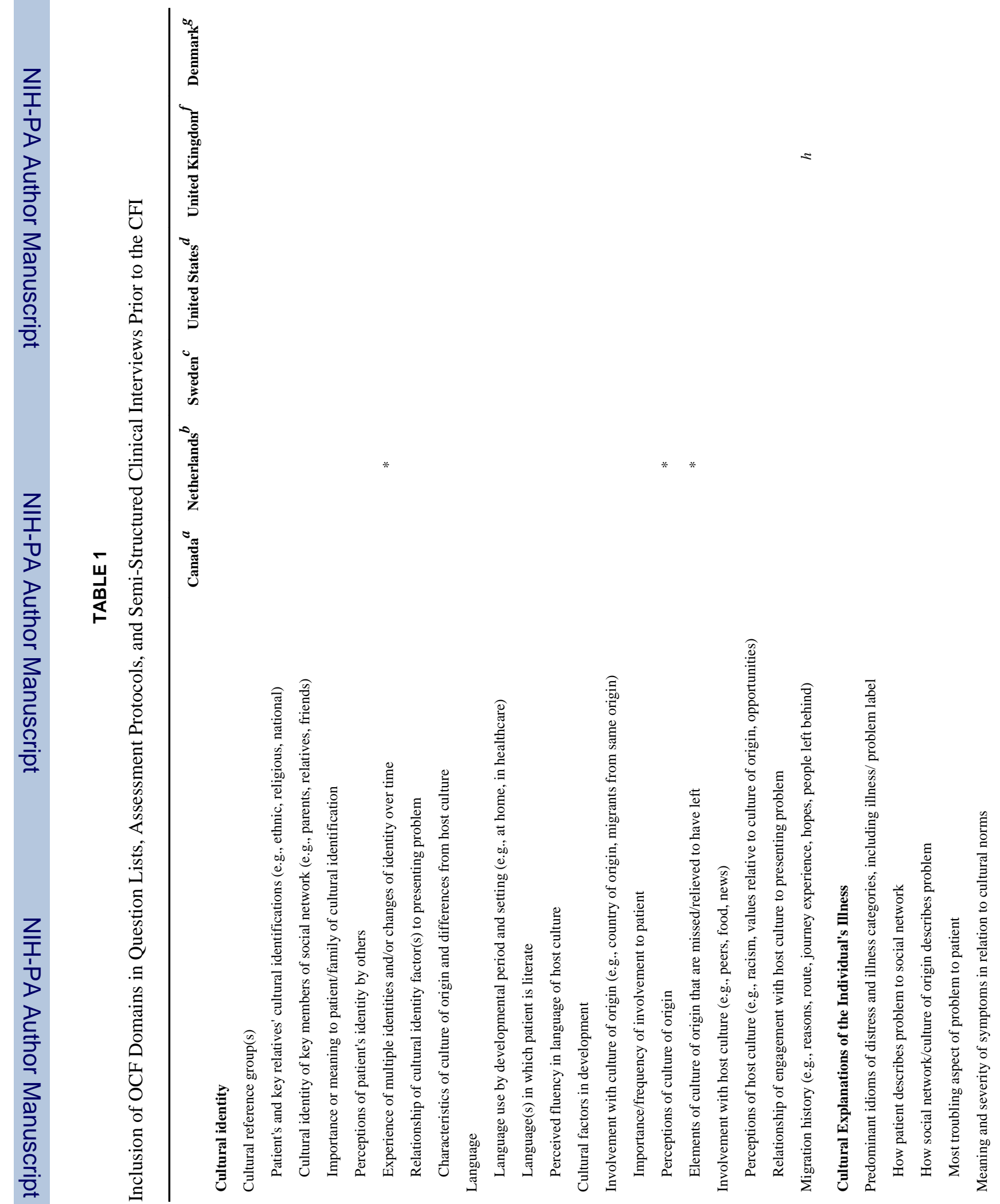


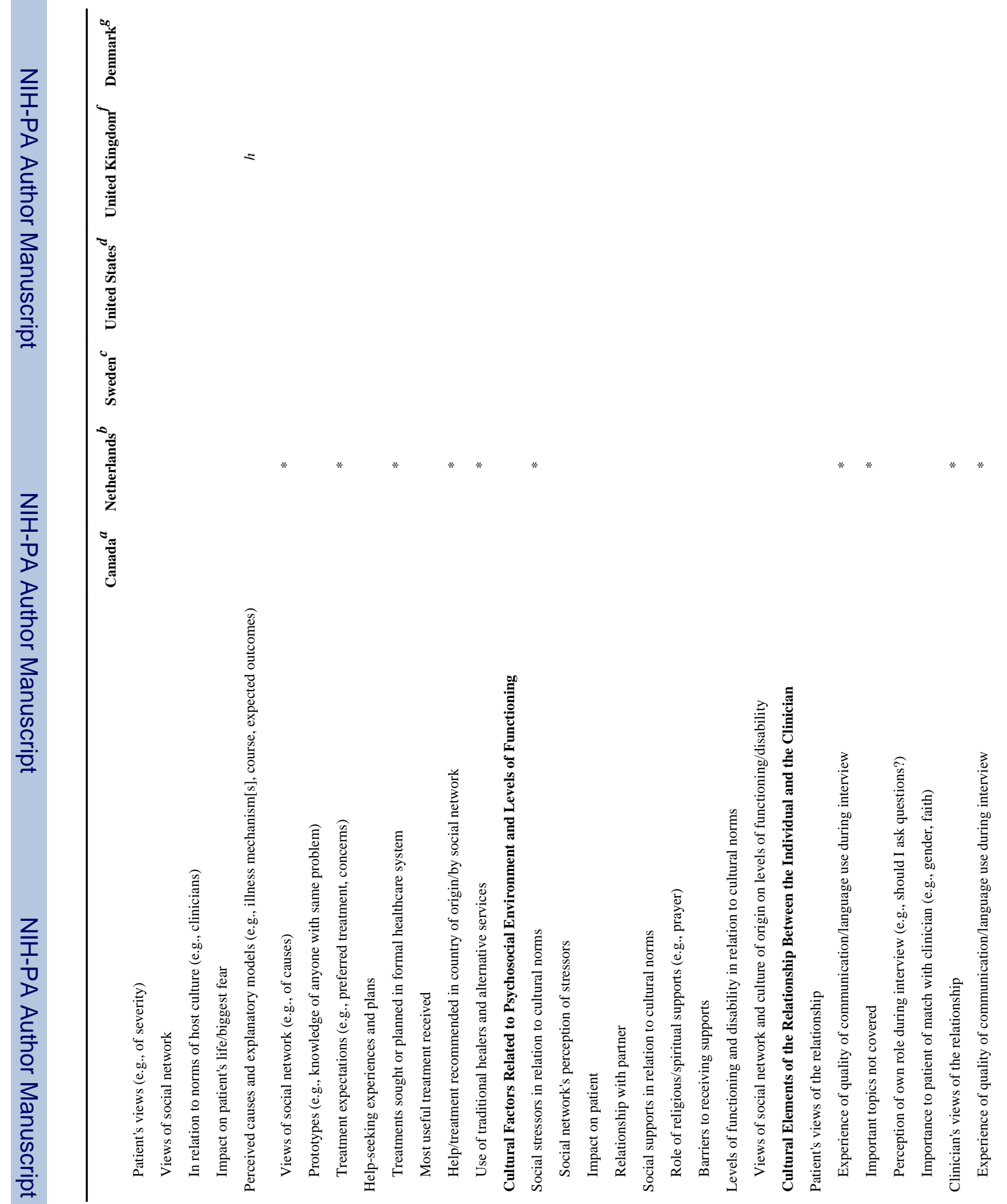




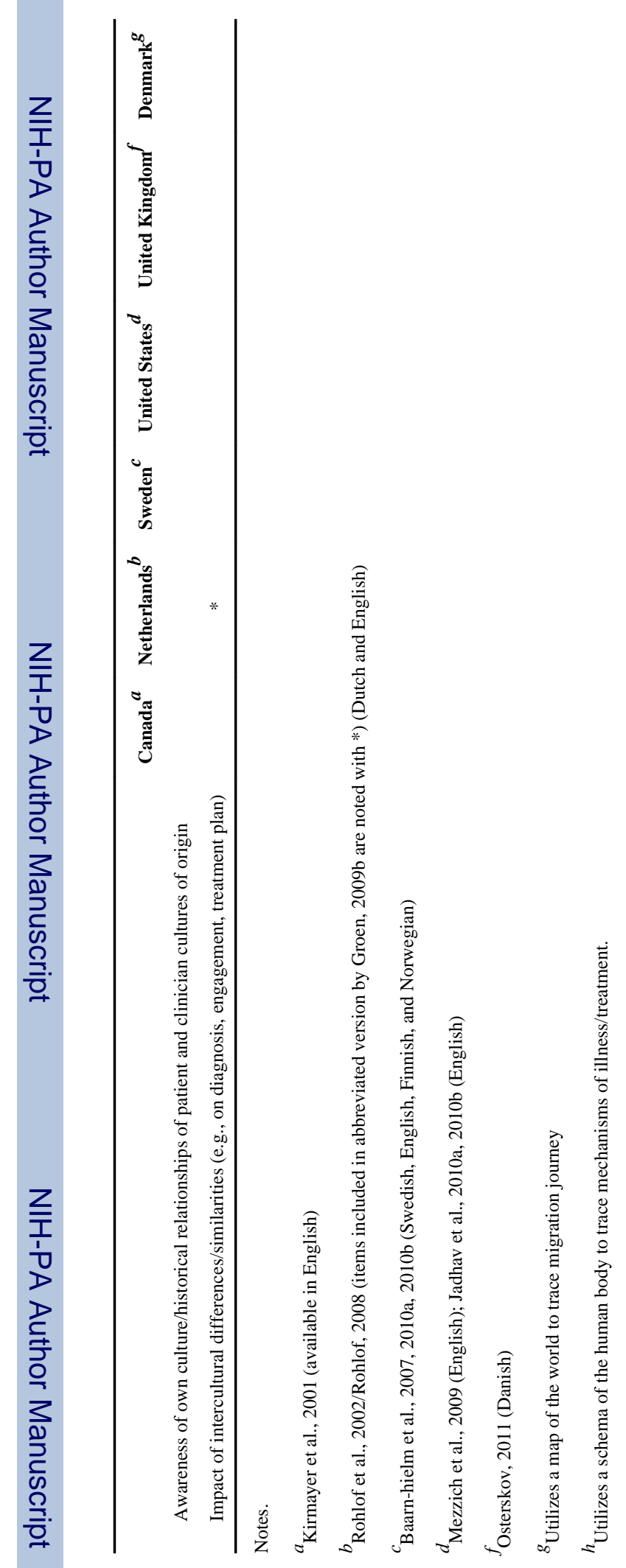

Psychiatry. Author manuscript; available in PMC 2015 February 17. 
TABLE 2

DSM-5 Supplementary Modules to the Core Cultural Formulation Interview

\begin{tabular}{ll}
\hline Number & Module \\
\hline 1 & Explanatory model \\
2 & Level of functioning \\
3 & Social network \\
4 & Psychosocial stressors \\
5 & Spirituality, religion, and moral traditions \\
6 & Cultural identity \\
7 & Coping and help-seeking \\
8 & Patient-clinician relationship \\
9 & School-age children and adolescents \\
10 & Older adults \\
11 & Immigrants and refugees \\
12 & Caregivers \\
\hline
\end{tabular}




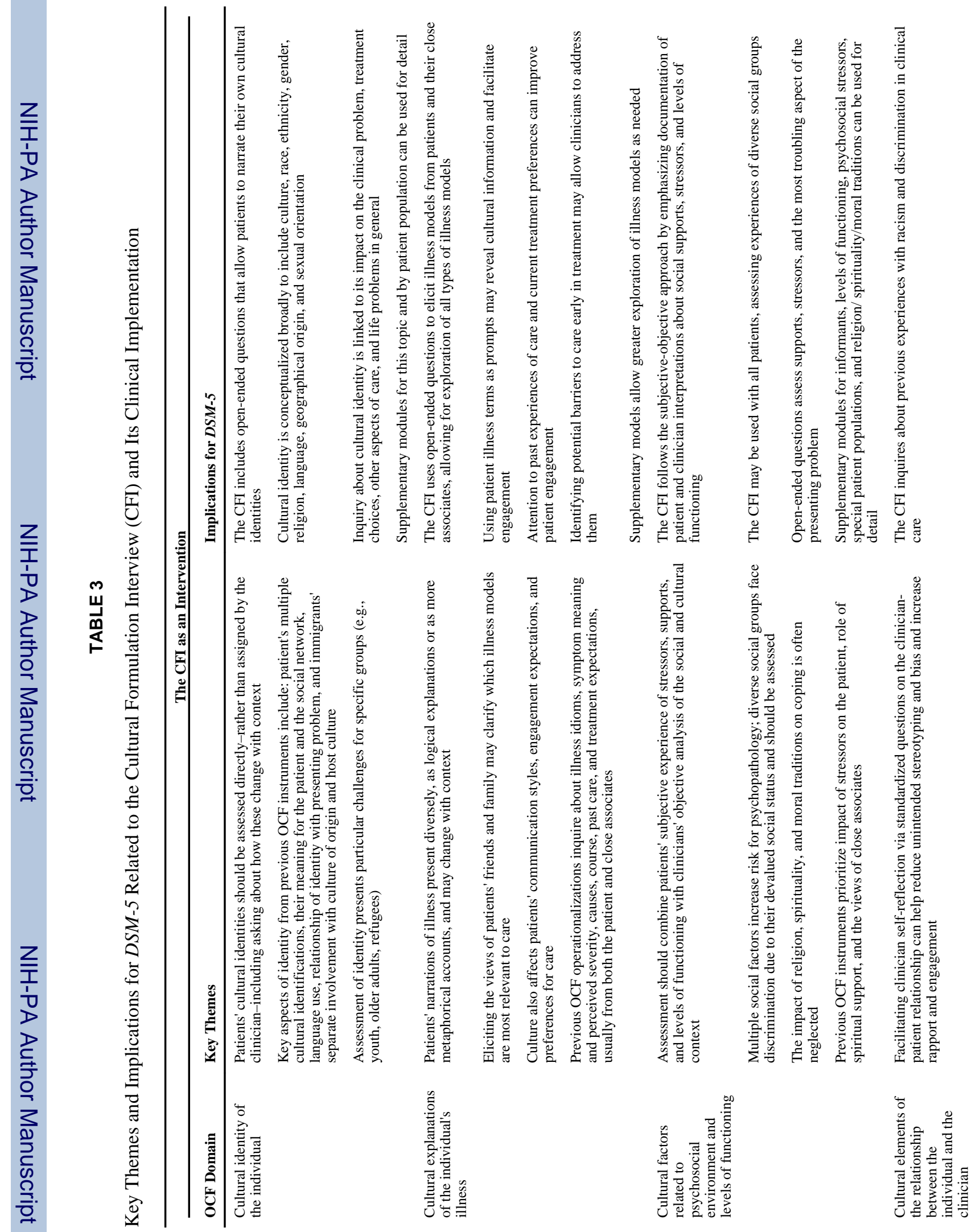


Lewis-Fernández et al.

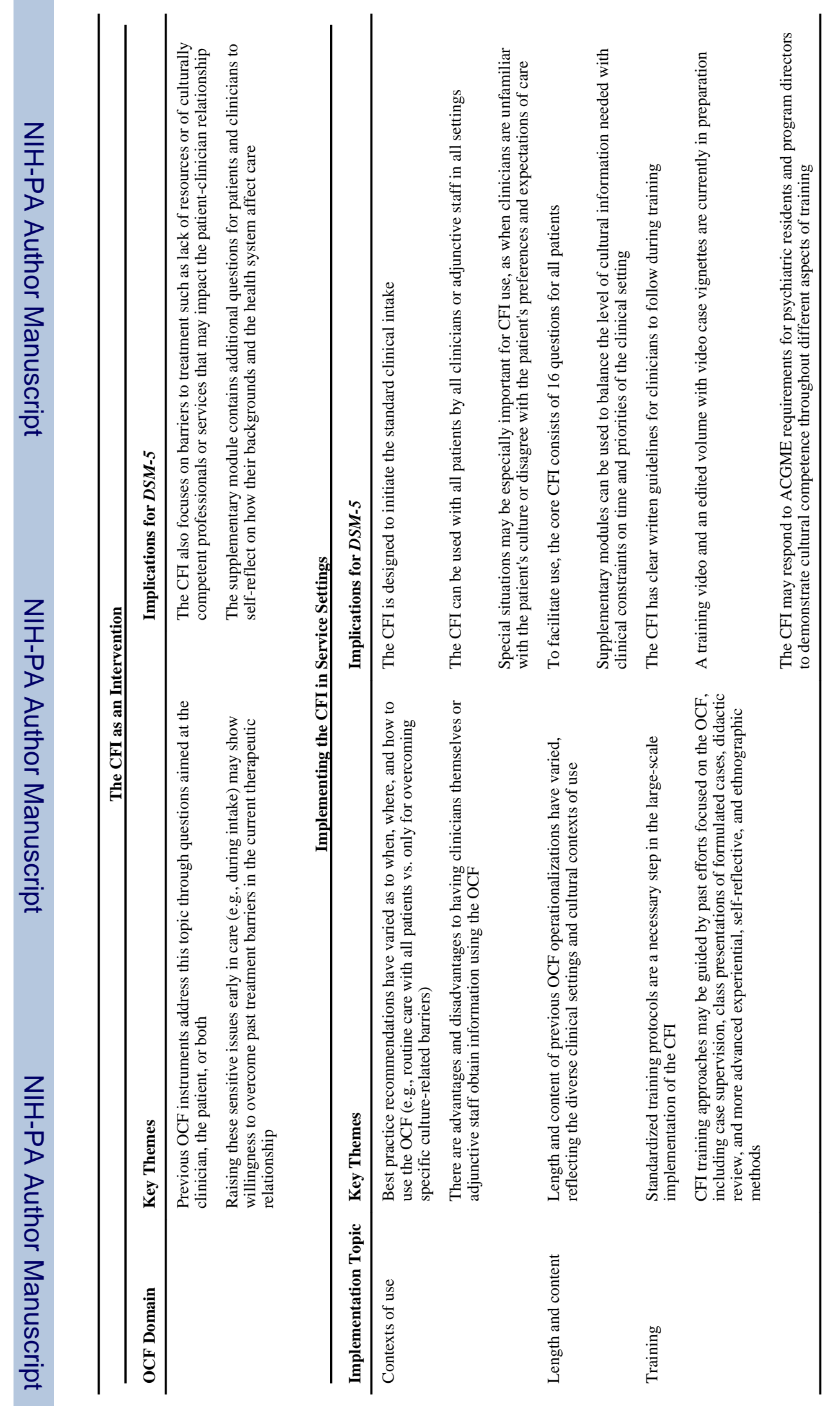

Psychiatry. Author manuscript; available in PMC 2015 February 17. 